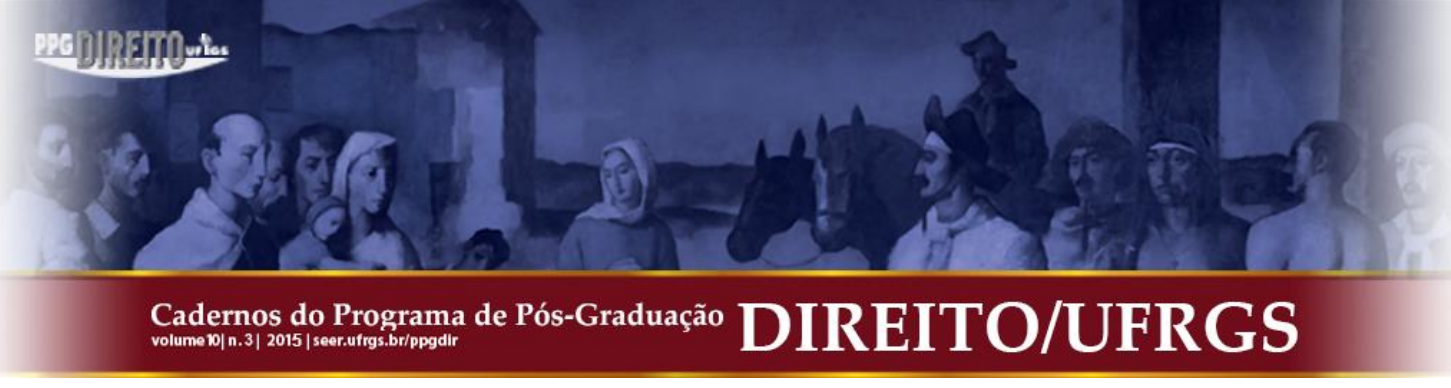

\title{
A ÚlTIMA PALAVRA E DIÁLOGO INSTITUCIONAL: RELAÇÕES COM AS TEORIAS DEMOCRÁTICAS EM DWORKIN E WALDRON
}

\author{
THE LAST WORD AND INSTITUTIONAL DIALOGUE: \\ RELATIONS WITH THE DEMOCRATIC THEORIES IN DWORKIN AND WALDRON
}

Fernando José Longo Filho*

\begin{abstract}
RESUMO: O propósito deste artigo é analisar as teorias democráticas de Dworkin e Waldron a fim de compreender como esses autores justificam normativamente os conceitos de última palavra e diálogo institucional. Dworkin é analisado como representante da perspectiva teórica do Poder Judiciário como o detentor da última palavra. Waldron é apresentado como o antagonista dessa perspectiva quando enfatiza o papel do Parlamento. Entretanto, embora sejam antagonistas quanto ao tema da última palavra, tanto Dworkin como Waldron têm convergências sobre o conceito de democracia. É a partir da análise dessas divergências e convergências que se pretende explorar a temática da última palavra e do diálogo institucional.
\end{abstract}

PALAVRAS-CHAVE: Diálogo institucional. Parlamento. Judiciário. Democracia.
ABSTRACT: The purpose of the essay is to analyze the democratic theories of Dworkin and Waldron in order to understand how these authors justify normatively the concepts of last word and institutional dialogue. Dworkin is analyzed as a representative of a theoretic approach to the Judiciary Branch as the owner of the last word. Waldron is presented as the antagonist of this approach when emphasizes the roll of the Parliament. However, despite the fact they are antagonists in relation to the topic of the last word, Dworkin as well as Waldron have convergences about the concept of democracy. It is from the analysis of these divergences and convergences that it is intended to explore the theme of the last word and institutional dialogue.

KEYWORDS: Institutional dialogue. Parliament. Judiciary. Democracy.

SUMÁRIO: Introdução. 1. A última palavra em Dworkin. 2. A última palavra em Waldron. 3. Democracia, última palavra e diálogo. Conclusões. Referências

\section{INTRODUÇÃO}

O conceito de diálogo institucional ingressou, recentemente, no debate jurídico internacional e nacional. ${ }^{1}$ Por diálogo institucional, entenda-se, em um primeiro momento e apenas como um conceito descritivo, a existência de uma interação entre Cortes Constitucionais e Parlamento na atividade de interpretar e dar sentido à Constituição.

\footnotetext{
* Mestrando em Direito pelo Instituto Brasiliense de Direito Público (IDP). Bacharel em Direito pela Universidade Federal da Bahia (UFBA). Procurador do Distrito Federal desde 2005.

${ }^{1}$ Conferir HOGG, Peter W. and BUSSELL, Alisson A. The charter dialogue between Courts and Legislatures. (Or perhaps The Charter of Rights isn't such a bad thing after all). Osgoode Law Journal, v. 35, n. 1, 1997. GARGARELlA, Roberto (comp.). Por una justicia dialógica. El Poder Judicial como promotor de la deliberación democrática. Buenos Aires: Siglo Veintiuno, 2014. MENDES, Conrado Hübner. Direitos fundamentais, separação de poderes e deliberação. Tese apresentada ao Departamento de Ciência Política da Faculdade de Filosofia, Letras e Ciências Humanas da Universidade de São Paulo para a obtenção do título de Doutor em Ciência Política. São Paulo: 2008. BRANDÃO, Rodrigo. Supremacia Judicial versus diálogos constitucionais: a quem cabe a última palavra sobre o sentido da Constituição? Rio de Janeiro: Lumen Juris, 2012. VICTOR, Sérgio Antônio Ferreira. Diálogo Institucional e Controle de Constitucionalidade: debate entre o STF e o Congresso Nacional. São Paulo: Saraiva, 2015.
} 


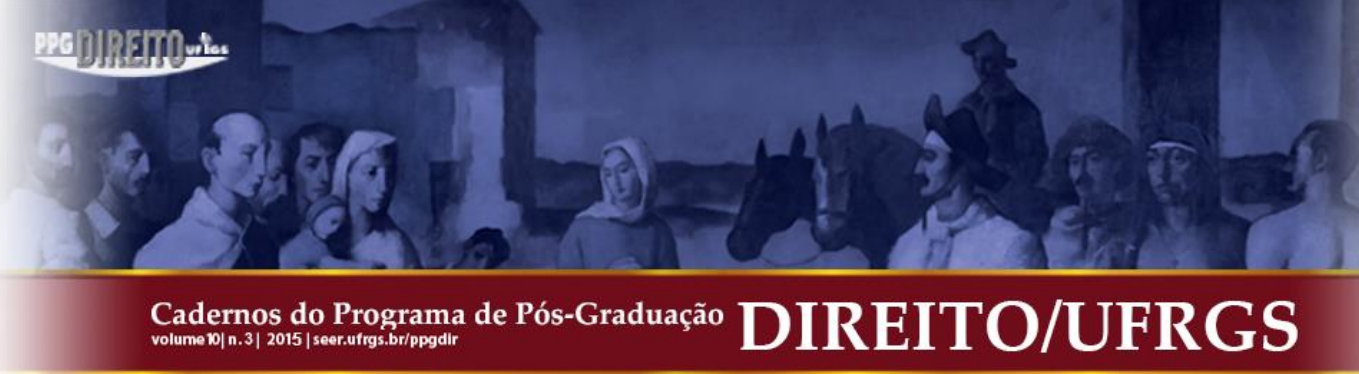

dialógico canadense implicou a adoção de outro modelo teórico de democracia. Recusou-se o modelo forte de judicial review norte-americano ${ }^{7}$, em que a Suprema Corte é protagonista em outorgar "a última palavra", sendo suas decisões superadas apenas por emenda constitucional, o que é extremamente difícil no caso dos EUA.

Esses modelos de judicial review estão assentados em concepções de democracia. E o objetivo desse ensaio é explorar a relação entre esses modelos de judicial review e teorias democráticas. Se, do ponto de vista descritivo, não há dúvida sobre a existência de uma interação entre Corte Constitucional e Parlamento; pela ótica da justificativa normativa, as alternativas variam de acordo com os modelos de democracia supostos.

Nesse contexto, será explorada as relações entre teoria democrática e o sistema forte de judicial review proposto por Dworkin. Em seguida, o autor a ser analisado é Jeremy Waldron que é um arquétipo teórico de defesa da supremacia do Parlamento e de rejeição da supremacia judicial, e pode ser definido como um antagonista de Dworkin.

Em seguida, serão exploradas as coincidências e as divergências entre Dworkin e Waldron, analisando-se como esses autores trabalham as categorias democracia, última palavra e diálogo. Embora esse último conceito não esteja presente como referência teórica expressa em nenhum dos dois autores, isto não significa que não tenham dito nada sobre a interação entre Parlamento e Corte Constitucional.

\section{A ÚLTIMA PALAVRA EM DWORKIN}

Dworkin reconhece que a supremacia judicial é um fato histórico da sociedade americana que considera o Poder Judiciário como o intérprete final da Constituição, cuja compreensão dos direitos fundamentais é a de um ordenamento principiológico. E argumenta que não há motivo para se forçar as práticas americanas a se amoldarem a uma filosofia majoritária. ${ }^{8}$

\footnotetext{
${ }^{7}$ Waldron propõe uma classificação de sistemas de judicial review em forte, médio e fraco. Os EUA e alguns países da Europa teriam um sistema forte de judicial review, em contraposição ao Reino Unido e Nova Zelândia, que teriam um sistema fraco. O Canadá é classificado como um sistema médio porque a cláusula "não obstante" impõe um ônus ao legislador. Conferir WALDRON, Jeremy. Judicial Review and Judicial Supremacy. New York University School of Law, Public Law \& Legal Theory Research Paper Series. Working Paper $\mathrm{n}^{\circ}$ 14-57, November 2014, p. 9-10.

${ }^{8}$ DWORKIN, Ronald. Freedom's Law. The Moral Reading of the American Constitution. Oxford University Press, 2005. p. 34-35.
}

Cadernos do Programa de Pós-Graduação em Direito PPGDir./UFRGS | Edição Digital | Porto Alegre | Volume X | Número 3 | 2015 | P. 90 - 111 


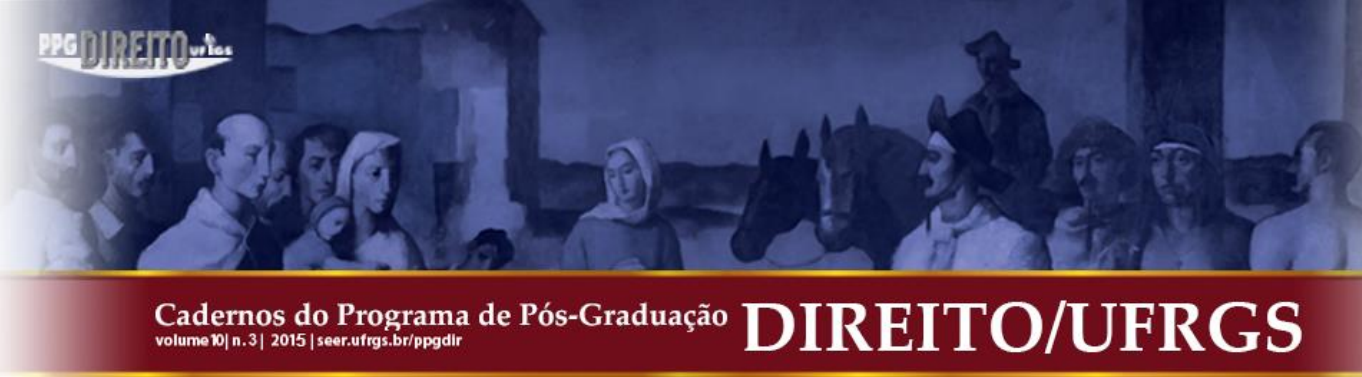

Apesar desse reconhecimento, o esforço teórico de Dworkin é para justificar a legitimidade democrática do judicial review, isto é, de que os direitos fundamentais podem ser usados como trunfos, na conhecida fórmula, para bloquear as decisões de política adotadas pela sociedade por meio dos órgãos da democracia representativa, cuja tese pode ser sintetizada da seguinte maneira nas suas próprias palavras ${ }^{9}$ :

\begin{abstract}
Minha visão é que o Tribunal deve tomar decisões de princípio, não de política decisões sobre que direitos as pessoas têm sob nosso sistema constitucional, não decisões sobre como se promove melhor o bem-estar geral -, e que deve tomar essas decisões elaborando e aplicando a teoria substantiva da representação, extraída do princípio básico de que o governo deve tratar as pessoas como iguais.
\end{abstract}

É a distinção entre argumentos de princípio e argumentos de política (policy). Cabe ao Poder Judiciário decidir de acordo com os argumentos de princípio. Para essa finalidade, Dworkin desenvolve a sua concepção de Direito como integridade e elabora uma sofisticada teoria da interpretação e aplicação do Direito. ${ }^{10}$ Embora seja questionável essa distinção tão demarcada entre princípios e política (policy) ${ }^{11}$, o que nos interessa é o fundamento que apoia o conceito de argumento de princípios e, por consequência, autoriza o judicial review. Tratase da concepção de democracia substantiva elaborada por Dworkin, formulada do seguinte modo:

\footnotetext{
Estamos, finalmente, em condições de examinar nossa hipótese de maneira direta: a melhor defesa da legitimidade política - o direito de uma comunidade política tratar seus membros como tendo obrigações em virtude de decisões coletivas da comunidade - vai ser encontrada não onde os filósofos esperam encontrá-la - no árido terreno dos contratos, dos deveres de justiça ou das obrigações de jogo limpo, que poderiam ser válidas entre os estranhos -, mas no campo mais fértil da fraternidade, da comunidade e de suas obrigações concomitantes. Como a família, a amizade e outras formas de associação mais íntimas e locais, a associação política contém a obrigação em seu cerne. ${ }^{12}$
}

Dworkin afasta-se de uma concepção contratualista de democracia em favor de um modelo fundado na fraternidade política, no caráter associativo da comunidade política. Essa distinção é mais nítida quando Dworkin diferencia dois tipos de ação coletiva: a estatística e a comunal. Quando se diz que a democracia é o governo do povo e pelo povo, supõe-se que os

\footnotetext{
${ }^{9}$ Id, Uma Questão de Princípio. São Paulo: Martins Fontes, 2000. p. 101.

${ }^{10} \mathrm{Id}$, O Império do Direito. São Paulo: Martins Fontes, 1999.

${ }^{11}$ VICTOR, Sérgio Antônio Ferreira. Op. cit. p. 164.

12 DWORKIN, Ronald. O Império do Direito. São Paulo: Martins Fontes, 1999. p. 249-250. Destaques nossos. Cadernos do Programa de Pós-Graduação em Direito PPGDir./UFRGS | Edição Digital | Porto Alegre | Volume X | Número 3 | 2015 | P. 90 - 111
} 


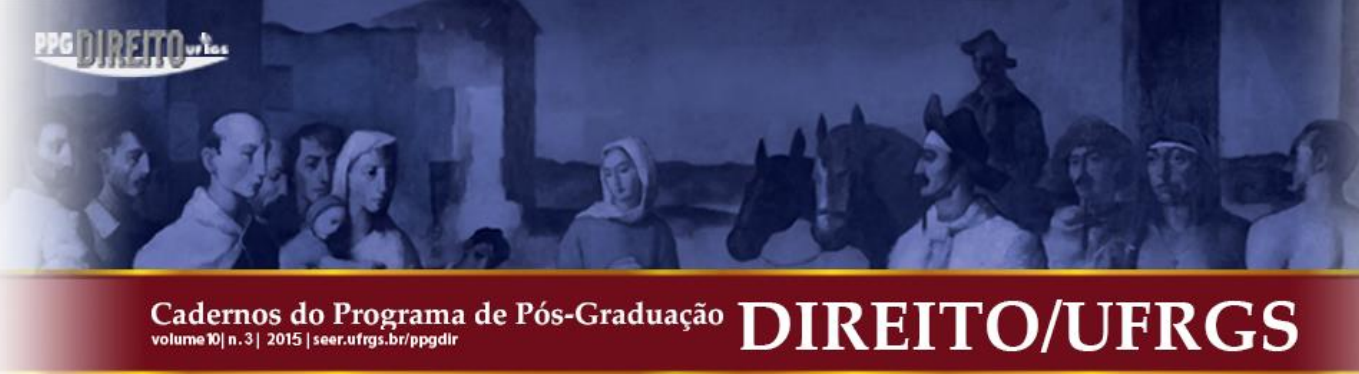

indivíduos atuem coletivamente, o que pode ocorrer de maneira estatística ou comunal. A depender de como seja a ação coletiva - se estatística ou comunal, a premissa majoritária irá se modificar, isto é, o modo como se concebe o funcionamento da democracia. ${ }^{13}$

Segundo Dworkin, a ação coletiva é estatística quando a atuação política considera apenas os indivíduos isoladamente, sem admitir a ação de um sujeito coletivo, o povo, como ator político. O sistema eleitoral de contagem de votos e formação de maiorias parlamentares é um exemplo de ação estatística que forja uma concepção majoritária de democracia. ${ }^{14} \mathrm{Em}$ outras palavras, o sistema de regras e processos eleitorais majoritários não explicam o conceito de democracia de Dworkin.

A ação coletiva comunal ou associativa é explicada com o exemplo da orquestra. Para que o desempenho de uma orquestra seja um sucesso, não basta apenas que os músicos toquem adequadamente seus instrumentos de maneira isolada; porém, é necessário que toquem como uma orquestra, isto é, cada um contribuindo para o desempenho do grupo e assumindo a sua responsabilidade coletiva nesse empreendimento. ${ }^{15}$

É com base nessa noção de ação coletiva comunal ou associativa que Dworkin constrói seu conceito de democracia constitucional. Afirma que para se ter um conceito de democracia é imprescindível que estejam presentes condições relacionais ${ }^{16}$ que são extraídas da noção de ação coletiva comunal ou associativa e explicitadas por Dworkin assim ${ }^{17}$ :

Uma comunidade política não pode considerar alguém como um membro moral a não ser que conceda a essa pessoa uma parte na decisão coletiva, uma participação nela e independência dessa decisão coletiva.

A primeira condição é a de participar da comunidade política, o que significa dizer que um membro da comunidade política deve ter assegurada a oportunidade de fazer diferença nas decisões coletivas. Essa condição implica garantir o direito de sufrágio universal, a legitimidade do processo eleitoral e o princípio da representatividade. Entretanto, não se

\footnotetext{
${ }^{13}$ Id, Freedom's Law. The Moral Reading of the American Constitution. Oxford University Press, 2005. p. 19.

${ }^{14}$ Ibid, p. 20.

15 Ibid, p. 20.

${ }^{16}$ Ao lado das condições relacionais, Dworkin afirma que são necessárias também as condições estruturais, que versam essencialmente sobre aspectos históricos. Nos deteremos aqui as condições relacionais por reputarmos mais importantes para a compreensão do conceito de democracia constitucional de Dworkin. Conferir DWORKIN, Ronald. Freedom's Law. The Moral Reading of the American Constitution. Oxford University Press, 2005. p. 23.

${ }^{17}$ Ibid, p. 24, tradução nossa livre do inglês: "A political community cannot count anyone as a moral member unless it gives that person a part in any collective decision, a stake in it, and independence from it."

Cadernos do Programa de Pós-Graduação em Direito PPGDir./UFRgS | Edição Digital | Porto Alegre | Volume X | Número 3 | 2015 | P. 90 - 111
} 


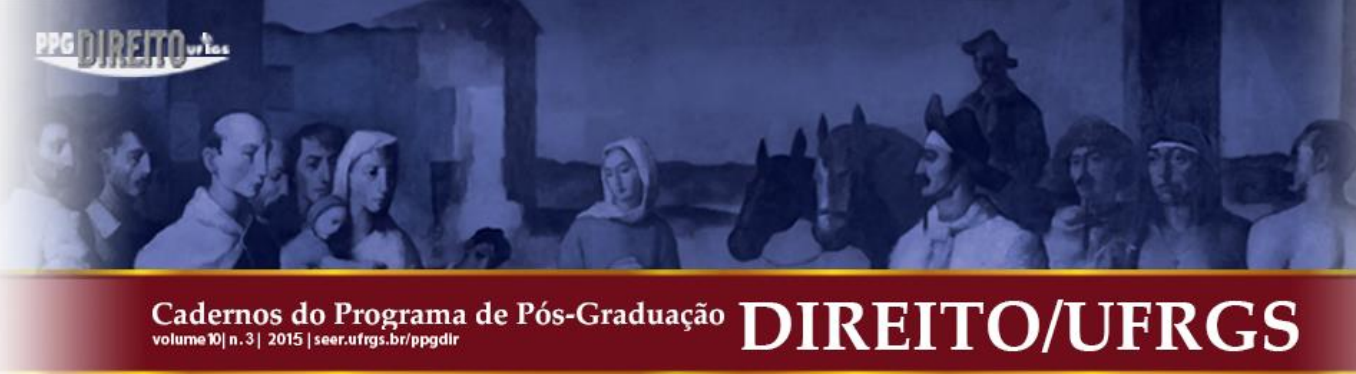

esgota nesses aspectos, abrangendo também o direito de liberdade de expressão que desempenha um importante papel no autogoverno. ${ }^{18}$

Prosseguindo, Dworkin assevera que a segunda condição corresponde ao fato de que uma comunidade política genuína deve expressar de boa-fé uma concepção de igual consideração pelos interesses de todos os membros, ou seja, as decisões políticas que afetam a distribuição de riquezas, benefícios e encargos devem considerar todos igualmente. ${ }^{19}$

A última condição - independência moral - seria a mais controvertida para Dworkin. Embora os membros dessa comunidade política sejam guiados por uma ação coletiva comunal ou associativa e, por esse motivo, são parceiros de uma aventura conjunta, uma comunidade política genuína é composta por indivíduos independentes moralmente, isto é, ninguém pode ditar regra sobre juízos éticos, morais ou políticos, mas, pelo contrário, deve encorajar as pessoas a alcançarem as suas convicções nesses assuntos por meio da sua própria reflexão e decisão individual. ${ }^{20}$ Dworkin se socorre novamente no exemplo da orquestra para explicar o conceito de independência moral. O regente tem o poder de decisão de como será interpretado um determinado trecho de uma peça musical e o músico não sacrifica nenhum aspecto de sua vida quando isso ocorre. Todavia, ocorrerá justamente o contrário quando o regente não apenas determina o que se tocará, mas procura ditar quais são os padrões de gostos musicais que o violinista deveria cultivar. Nessa última hipótese, tem-se a violação da independência moral do membro da comunidade política. ${ }^{21}$

E o que é o Direito como integridade? Não é a compreensão do Direito apenas como um sistema de regras convencionais, destinado a conferir estabilidade e previsibilidade, tendo, portanto, caráter meramente instrumental. Trata-se de entender que a força política do Direito nasce porque ele está destinado a assegurar a igual consideração de todos os indivíduos na comunidade política. ${ }^{22}$ Essa é a integridade do Direito para Dworkin. Como se verifica, o conceito de integridade do Direito deriva da concepção de democracia substancial de Dworkin.

A integridade do Direito corresponde a justificativa moral para o uso da coerção estatal. E esse é um aspecto que, segundo Dworkin, passa despercebido pelos filósofos do

\footnotetext{
${ }^{18}$ Ibid, p. 25.

${ }^{19}$ Ibid, p. 25.

${ }^{20}$ Ibid, p. 25-26.

${ }^{21}$ Ibid, p. 26.

${ }^{22}$ Id, O Império do Direito. São Paulo: Martins Fontes, 1999. p. 120.
}

Cadernos do Programa de Pós-Graduação em Direito PPGDir./UFRGS | Edição Digital | Porto Alegre | Volume X | Número 3 | 2015 | P. 90 - 111 


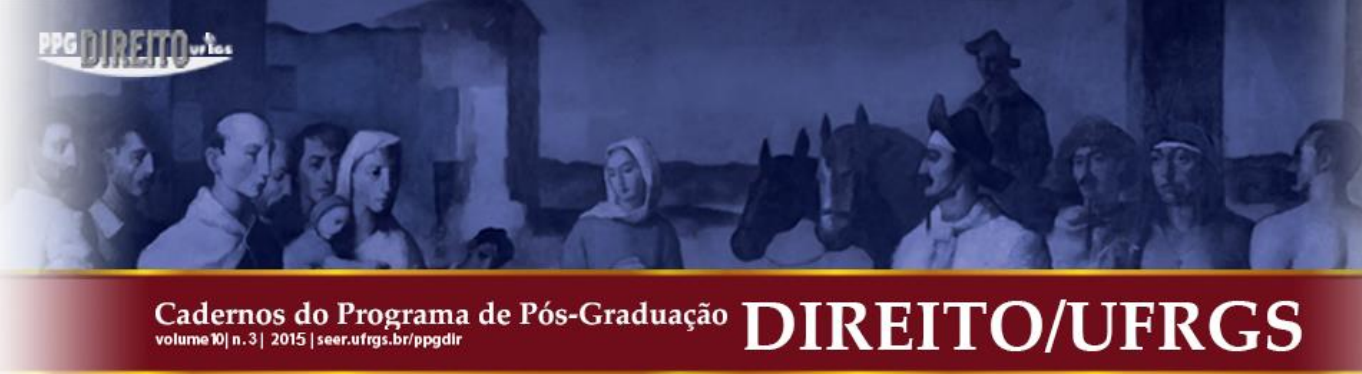

Direito. Argumenta que há uma espécie de divisão do trabalho. Os cientistas políticos se ocupam dos problemas relativos à força do Direito, ou seja, da justificativa para a coerção estatal. Os filósofos do Direito se dedicam aos fundamentos do direito - "circunstâncias nas quais proposições jurídicas específicas devem ser aceitas como bem fundadas ou verdadeiras". ${ }^{23}$

Nesse contexto, Dworkin assevera que o Direito entendido apenas como um sistema de regras baseado em um modelo convencionalista supõe uma atuação egoística de seus membros. Confira-se ${ }^{24}$ :

Chamo modelo 'das regras' ao segundo modelo de comunidade. Pressupõe que os membros de uma comunidade política aceitam o compromisso geral de obedecer às regras estabelecidas de um certo modo que é específico dessa comunidade. Imaginemos pessoas voltadas para os seus próprios interesses, mas extremamente honestas, que competem em um jogo, ou que constituem as partes de um acordo comercial limitado e provisório. Elas obedecem às regras que aceitaram ou negociaram como uma questão de obrigação, e não de mera estratégia, mas admitem que o conteúdo dessas regras esgota sua obrigação.

Por essa razão, Dworkin argumenta que a integridade do Direito implica a adoção de uma associação política guiada por princípios, ou seja, um fórum de princípios. É o modelo da comunidade de princípios que atende a todas condições da democracia substancial de Dworkin, em que todos devem ter igual consideração e são responsáveis pela aplicação do Direito naquela associação política. ${ }^{25} \mathrm{E}$ nessa lógica, Dworkin arremata afirmando que a obrigação política adquire uma ideia de fidelidade a um sistema de princípios ${ }^{26}$ :

\footnotetext{
A obrigação política deixa de ser, portanto, apenas uma questão de obedecer a cada uma das decisões políticas da comunidade, como, em geral a representam os filósofos políticos. Torna-se uma ideia mais impregnada da noção protestante de fidelidade a um sistema de princípios que cada cidadão tem a responsabilidade de identificar, em última instância para si mesmo, como o sistema de comunidade à qual pertence.
}

Com fundamento nessa compreensão de democracia constitucional e de integridade do Direito, Dworkin propugna por um conceito de leitura moral da Constituição, cujo objetivo é elaborar uma teoria de como as constituições devem ser interpretadas, o que implica em

\footnotetext{
${ }^{23}$ Ibid, p. 136-137.

${ }^{24}$ Ibid, p. 253.

${ }^{25}$ Ibid, p. 256-257.

${ }^{26}$ Ibid, p. 231.
}

Cadernos do Programa de Pós-Graduação em Direito PPGDir./UfRgS | Edição Digital | Porto Alegre | Volume X | Número 3 | 2015 | P. 90 - 111 


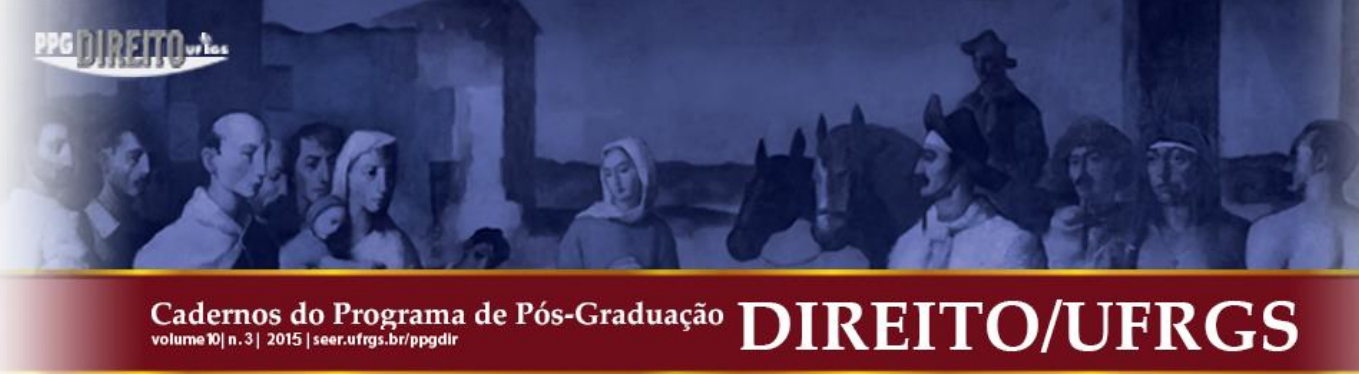

identificar quais as questões devem ser formuladas e respondidas ao se interpretar a Constituição. A leitura moral não é uma teoria sobre quem faz perguntas ou sobre de quem deve ter a palavra final sobre a Constituição. ${ }^{27}$ Esse aspecto é relevante. Dworkin elabora uma sofisticada teoria de interpretação da Constitucional. Todavia, isso não significa que Dworkin não tenha dito nada sobre quem deva ter a última palavra sobre a Constituição.

Dworkin trabalha com os conceitos de integridade na legislação e integridade na deliberação judicial. Afirma que o legislador deve se guiar pela integridade, mas, em algumas ocasiões, a integridade pode ceder em face da justiça. ${ }^{28}$ Menciona como exemplo o caso hipotético de uma lei aprovada pelo legislador que considera que a indenização por automóveis defeituosos ocorre com base na responsabilidade objetiva. Afirma que a integridade exigiria que se aprovasse uma lei para todos os outros produtos. Entretanto, essa proposição provavelmente levaria muito tempo para ser aprovada. Os outros fabricantes teriam resistência na aprovação dessa lei. Assim, ele conclui que, nesse caso, a integridade condena o resultado, mas a justiça aprova porque antes pouco do que nada. ${ }^{29}$

O conceito de integridade na deliberação judicial exige que os juízes tratem o sistema jurídico como um conjunto coerente de princípios, interpretando-o, de modo, a identificar as normas implícitas. ${ }^{30}$ Afirma que a integridade na deliberação judicial não imuniza o Judiciário de se equivocar, porém conclui que ${ }^{31}$ :

O princípio de integridade na deliberação judicial, portanto, não tem necessariamente a última palavra sobre de que modo usar o poder de coerção do Estado. Mas tem a primeira palavra, e normalmente não há nada a acrescentar àquilo que diz.

Portanto, para Dworkin, o Judiciário não tem a última palavra, mas a primeira palavra e se trata de uma palavra altamente qualificada, pois assevera que normalmente não há nada acrescentar a interpretação do Poder Judiciário. É a desconfiança de Dworkin com o

\footnotetext{
${ }^{27}$ Id, Freedom's Law. The Moral Reading of the American Constitution. Oxford University Press, 2005. p. 34.

28 "Para nós, a integridade é uma virtude ao lado da justiça, da equidade e do devido processo legal, mas isso não significa que, em alguma das duas formas assinaladas, a integridade seja necessariamente, ou sempre superior às outras virtudes. O legislativo deveria ser guiado pelo princípio legislativo da integridade, e isso explica por que não deve promulgar leis conciliatórias apenas por uma preocupação com a equidade. Contudo, as leis conciliatórias constituem uma violação flagrante - e fácil de evitar - da integridade; daí não se segue que o legislativo nunca deve, sejam quais forem as circunstâncias, tornar o direito mais incoerente em princípio do que ele já é. (...)". Id, O Império do Direito. São Paulo: Martins Fontes, 1999 p. 261-262.

${ }^{29}$ Ibid, p. 262.

${ }^{30}$ Ibid, p. 261.

${ }^{31}$ Ibid, p. 263.
}

Cadernos do Programa de Pós-Graduação em Direito PPGDir./UFRGS | Edição Digital | Porto Alegre | Volume X | Número 3 | 2015 | P. 90 -111 


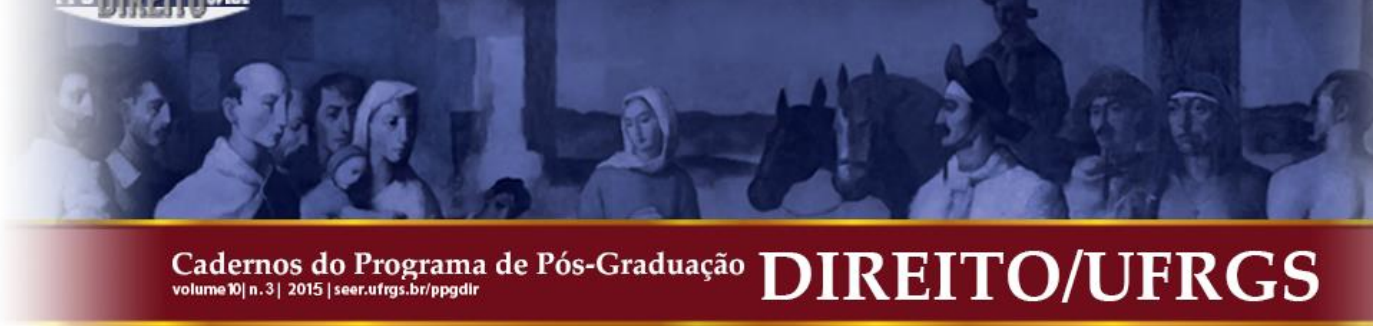

legislador. Contudo, Dworkin reconhece que os juízes erram e, nessas hipóteses, parece que a alternativa que resta para preservar a integridade do Direito é a desobediência civil. Confira$\mathrm{se}^{32}$ :

\begin{abstract}
O argumento que exorto os alemães a adotar, de que o direito, bem compreendido, pode apoiar o que chamamos de desobediência civil, só pode ser um argumento efetivo quando rejeitamos esse aspecto do positivismo e insistimos em que, embora os tribunais possam ter a última palavra, em qualquer caso específico, sobre o que é o direito, a última palavra não é, por essa razão apenas, a palavra certa.
\end{abstract}

Desse modo, para Dworkin, o Judiciário tem a primeira palavra qualificada em que, geralmente, não há nada a se acrescentar; ou a última palavra, o que significa dizer que se os juízes errarem, resta a desobediência civil para se preservar a integridade do Direito. A concepção de democracia de Dworkin implica, na prática, conferir a última palavra ao Judiciário.

\title{
2 A ÚLTIMA PALAVRA EM WALDRON
}

Waldron é um filósofo do Direito nascido na Nova Zelândia; logo, de um país pertencente a tradição de supremacia do Parlamento, típico dos países vinculados ao Reino Unido. Waldron critica veementemente a pratica do judicial review, isto é, a atribuição de juízes não eleitos declararem a nulidade de leis aprovadas por parlamentos constituídos democraticamente. ${ }^{33}$

Apesar dessa crítica, não ignora a realidade da existência de sistemas de judicial review, inclusive classificando-os em forte, intermediário e fraco. ${ }^{34}$ Entretanto, faz uma distinção entre judicial review e judicial supremacy. Entende que judicial review pode operar no melhor das vezes como um modesto poder de contenção; enquanto, a ideia de judicial supremacy implica que os juízes devem ser supremos ou até mesmo soberanos na política e que todos os outros Poderes constituídos devem ser subordinados a eles. ${ }^{35}$ Esclarece, por exemplo, que a Suprema Corte Americana tem se inclinado para o judicial supremacy não em

\footnotetext{
${ }^{32}$ Ibid., Uma Questão de Princípio. São Paulo: Martins Fontes, 2000, pág.171. Destaques nossos.

${ }^{33}$ WALDRON, Jeremy. Judicial Review and Judicial Supremacy. New York University School of Law, Public Law \& Legal Theory Research Paper Series. Working Paper n 14-57, November 2014. p. 4.

${ }^{34}$ Ibid, p. 9-10.

35 Ibid, p. 5.
}

Cadernos do Programa de Pós-Graduação em Direito PPGDir./UFRgS | Edição Digital | Porto Alegre | Volume X | Número 3 | 2015 | P. 90 - 111 


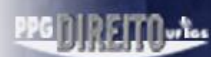

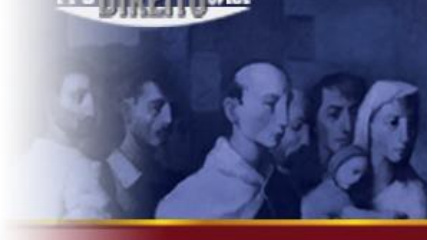

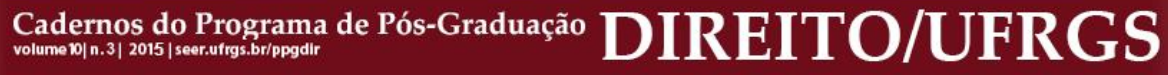

razão de se caracterizar por um sistema forte de judicial review, mas em virtude do modo como tem exercitado esse sistema forte de judicial review. ${ }^{36}$

Assevera que a supremacia judicial implica o deslocamento do autogoverno, a criação de uma soberania judicial e a usurpação do poder constituinte. ${ }^{37}$ A supremacia judicial tem a tendência de retirar do povo e de seus representantes o amplo poder de deliberar e decidir sobre a futura direção das instituições políticas, econômicas e sociais. ${ }^{38}$

Além disso, a supremacia judicial, segundo Waldron, pode ser definida como soberania judicial, ou seja, o Poder Judiciário encontra-se como pleno detentor do poder de dar a última palavra. De acordo com Hobbes, o problema da soberania significa identificar aquele poder que não se sujeita a nenhum outro, isto é, um poder que é fonte de toda coerção normativa e que não está contido por nenhum outro poder a não ser por si mesmo. ${ }^{39} \mathrm{~A}$ solução hobbesiana é a do Rule of Law - atribui-se a soberania ao Monarca ou ao Parlamento, o que é explicado pelo raciocínio de que a soberania não é limitada pelo texto constitucional, mas por um ente político. Portanto, segundo Hobbes, ou se tem o Monarca ou o Parlamento como detentor da soberania. A rejeição de leis pelo Poder Judiciário dissolve a construção de Hobbes da soberania como o Rule of Law e implica atribuir ao Poder Judiciário a soberania. É isso que Waldron denomina de supremacia judicial. ${ }^{40}$

Por fim, Waldron afirma que a supremacia judicial corresponde a uma usurpação do poder constituinte. Relembra que o Poder Judiciário, assim como os demais Poderes, são poderes constituídos. E por essa razão, os juízes ao decidirem devem se perguntar até que ponto estão repudiando interpretações da Constituição que emanam de outros poderes com base em suas próprias convicções. ${ }^{41}$ É o perigo do Judiciário se tornar a "voz" da Constituição. ${ }^{42}$

Para Waldron, o sistema de judicial review tende à supremacia judicial quando as cortes pensam e se apresentam como agentes que estão implementando um programa ou política coerente em vez de simplesmente responder a abusos particulares identificados em

\footnotetext{
${ }^{36}$ Ibid, p. 11

${ }^{37}$ Ibid, p. 12-24.

${ }^{38}$ Ibid, p. 13.

${ }^{39}$ Ibid, p. 15.

${ }^{40}$ Ibid, p. 17.

${ }^{41}$ Ibid, p. 24.

${ }^{42}$ Ibid, p. 37.
} 


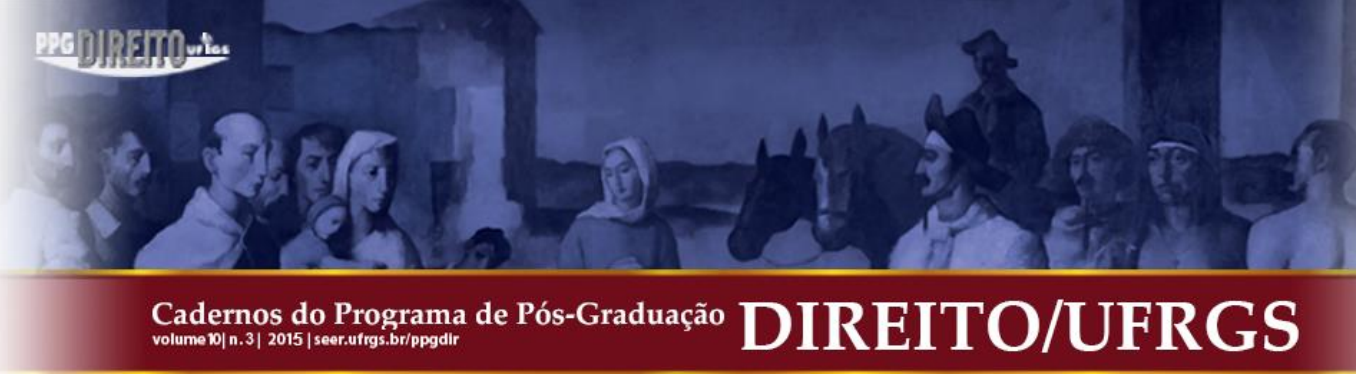

um catálogo de direitos de fundamentais. ${ }^{43}$ Essa inclinação também pode ocorrer quando os juízes se consideram os "donos" da Constituição, enquanto os demais Poderes e o povo não teriam direito a uma interpretação consistente da Constituição. ${ }^{44}$

A ofensiva contra a supremacia judicial é contra a prerrogativa que se outorgou ao Judiciário de ter a última palavra sobre a Constituição. Nesse sentido, Waldron menciona os casos envolvendo a liberdade religiosa nos EUA. ${ }^{45}$ Explica que a liberdade religiosa pode ser compreendida de duas maneiras pelos filósofos liberais: (1) como um direito de evitar a existência de uma legislação que pretende impor um ônus sobre a prática religiosa de alguém; ou (2) como um direito de evitar a legislação que imponha um ônus sobre a prática religiosa, independentemente de existir a pretensão de criar esse ônus ou não. No caso Employment Division v. Smith, a Suprema Corte americana se inclinou pela posição (1) que é mais restritiva em relação ao direito de liberdade religiosa. A Corte declarou a constitucionalidade de uma restrição imposta por lei que vedava a concessão de seguro desemprego a empregados demitidos em razão do uso do peiote (substância alucinógena utilizada em alguns rituais dos índios americanos).

Essa decisão gerou uma forte reação na sociedade americana, o que implicou a aprovação do Freedom Religious Restauration Act (FRRA) pelo congresso que, na prática, reverteu a decisão da Suprema Corte americana ao disciplinar que as leis gerais restritivas à liberdade religiosa devem ser submetidas ao critério (2), ou seja, a um escrutínio judicial mais rigoroso, pois, mesmo que o objetivo não seja restringir a liberdade religiosa, caso isso ocorra, devem ser declaradas inconstitucionais. No caso City of Boerne v. Flores, a Corte declarou a inconstitucionalidade do FRRA porque o Parlamento estaria almejando corrigir a decisão da Corte. Diante desses casos, Waldron se indaga porque uma questão nuclear que está em aberto no texto constitucional tem que ser definida pelo Judiciário e não pelo Parlamento eleito democraticamente. ${ }^{46}$ É a defesa intransigente de Waldron da dignidade da legislação. E o que confere dignidade à legislação?

$\mathrm{O}$ argumento de Waldron é de que a dignidade da legislação repousa no fato de que discordamos e a legislação são os nossos acordos compartilhados. O Direito Positivo introduz aquilo que o Direito Natural não pode fornecer: previsibilidade e estabilidade. Por meio do

\footnotetext{
${ }^{43}$ Ibid, p. 27.

${ }^{44}$ Ibid, p. 32.

${ }^{45}$ Ibid, p. 34-37.

${ }^{46}$ Ibid, p. 36.
} 


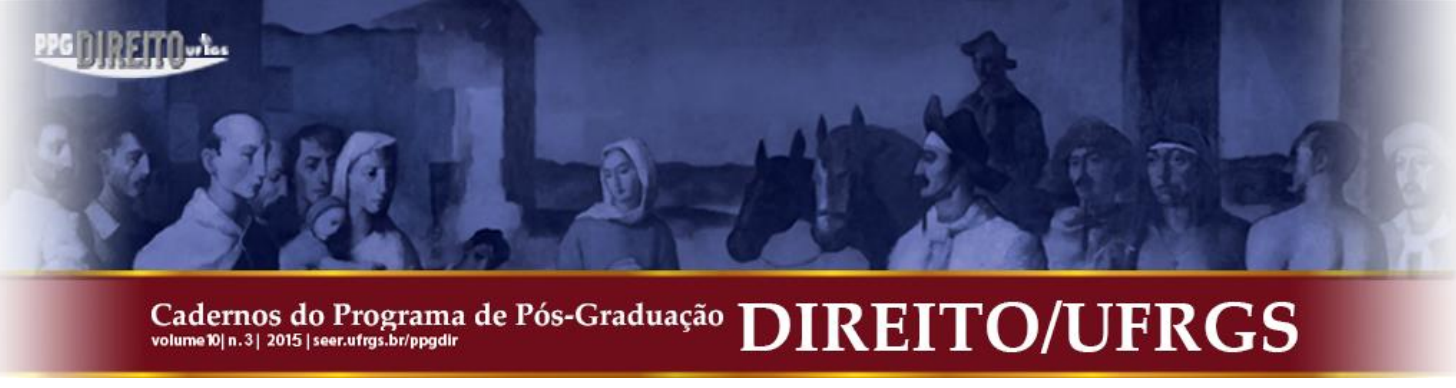

Direito Positivo, as mudanças são deliberadas ${ }^{47}$, o que não pode ser desprezado, uma vez que existe uma série e firme discordância sobre questões morais na sociedade.

A premissa fundamental de Waldron é a discordância sobre questões de política e justiça, o que não significa a existência de um subjetivismo, isto é, a impossibilidade de se ter respostas corretas. Entretanto, nega que a possibilidade de se obter a resposta correta sobre questões de justiça a partir de uma maneira politicamente dispositiva. ${ }^{48}$ Essa é a crítica de Waldron a Rawls com a sua perspectiva de posição original e seus princípios de justiça. ${ }^{49} \mathrm{O}$ raciocínio de Waldron é no sentido de que os membros da legislatura podem discordar inclusive a respeito dos princípios fundamentais da justiça. ${ }^{50}$ Prossegue afirmando que a discordância é uma circunstância da política, isto é, um atributo sem o qual não se pode cogitar de política. Confira-se ${ }^{51}$ :

\begin{abstract}
Podemos dizer, nessa maneira linha, que a discordância entre os cidadãos quanto ao que devem fazer, como corpo político, é uma das circunstâncias da política. Não é totalmente circunstâncias da política, é claro: há também a necessidade sentida de agir conjuntamente, embora discordemos quanto ao que fazer. Como a escassez e o altruísmo limitado no caso da justiça, as circunstâncias da política são um par conjugado: a discordância não teria importância se as pessoas não preferissem uma decisão comum, e a necessidade de uma decisão comum não daria à política como a conhecemos se não houvesse pelo menos o potencial para a discordância quanto a qual deve ser a decisão comum. Nessa exposição, imaginar eliminada a discordância é como deseja eliminar a escassez em qualquer exposição de justiça distributiva.
\end{abstract}

A outra circunstância da política é a decisão comum, isto é, a necessidade de uma ação política coletiva que implique a adoção de uma visão comum no “calor das nossas discordâncias, não fundamentada na suposição de um consenso sereno que existe apenas como ideal". 52 É o lugar dos membros do legislativo em que as mudanças são intencionadas e deliberadas pelo direito positivo. Significa adotar o critério majoritário para decidir sobre as discordâncias. E, nesse ponto, resta a indagação de qual é a justificativa para o critério majoritário.

Waldron repudia uma concepção teórica que denomina de fisicalista, cuja ideia central é de que um corpo se move por ordem da maioria porque a maioria é mais forte. É uma

\footnotetext{
${ }^{47}$ WALDRON, Jeremy. A dignidade da legislação. São Paulo: Editora Martins Fontes, 2003. p. 17.

${ }^{48}$ Ibid, p. 61.

${ }^{49}$ Ibid, p. 86-89.

${ }^{50}$ Ibid, p. 88.

${ }^{51}$ Ibid, p. 187. Destaques nossos.

${ }^{52}$ Ibid, p. 189.
}

Cadernos do Programa de Pós-Graduação em Direito PPGDir./UFRGS | Edição Digital | Porto Alegre | Volume X | Número 3 | 2015 | P. 90 - 111 


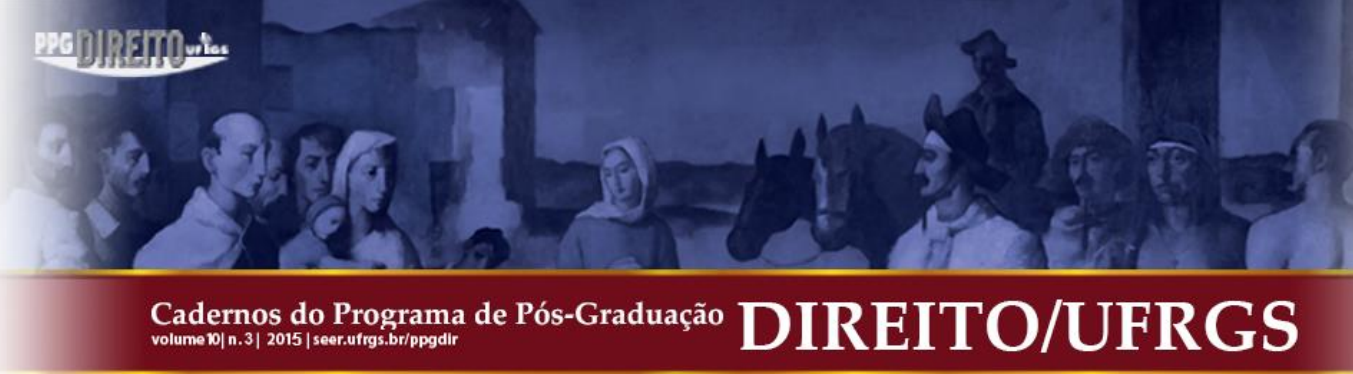

constituição dessa instância legisladora está inexoravelmente vinculado ao conceito de consentimento individual, porquanto os homens ainda permanecem livres. ${ }^{58}$

A física do consentimento individual tem consequências na leitura que se faz dos pressupostos da vida política de uma sociedade. Primeiro, a coesão do corpo político é assentada no compromisso implícito com o consentimento individual e não mais na força física, isto é, o consentimento original significa que os homens podem ser obrigados por uma decisão política da comunidade fundada no consentimento individual, ainda que seja majoritária. Por ser necessário o consentimento individual, existe uma lógica racional e baseada em motivos e razões para consentir. O que significa ainda, de acordo com Waldron, que há limites ao consentimento, ou seja, existem direitos inalienáveis que estão excluídos da disputa política, ainda que haja discordância sobre quais são esses direitos. ${ }^{59}$

O segundo pressuposto é o da direção tomada pelo corpo político. Uma concepção fisicalista supõe que a direção será o mero resultado do choque das direções apontadas pela maioria e minoria. A física do consentimento tem como força motriz da política de que o corpo político deve mover-se apenas na direção que foi explicitamente proposta e em que alguém consentiu com a proposta. ${ }^{60}$

O terceiro pressuposto relaciona-se com o conceito de igualdade formal. À luz de uma visão meramente fisicalista, a igualdade formal encobre as diferenças materiais que influenciam a direção do corpo político. Contudo, pela lógica da física do consentimento, a igualdade formal é justificada normativamente pelo aspecto de que o consentimento é uma questão de autoridade e legitimidade individual. ${ }^{61}$

E como a física do consentimento justifica a adoção de um sistema deliberativo majoritário? Por uma concepção fisicalista, a simples agregação de consentimentos justificaria um sistema majoritário. Recorde-se que Waldron não abre mão de seu argumento discordância. Os homens discordam sobre questões de justiça e precisam tomar decisões coletivas. Então, qual é a maneira mais adequada de proceder? Waldron responde ${ }^{62}$ :

Quando colocamos a questão dessa maneira, parece que podemos nos mover diretamente para o princípio majoritário como a resposta evidente. Pois pode ser

\footnotetext{
${ }^{58}$ Ibid, p. 167-168.

${ }^{59}$ Ibid, p. 169-172.

${ }^{60}$ Ibid, p. 173.

${ }^{61}$ Ibid, p. 174-175.

62 Ibid, p. 180.
}

Cadernos do Programa de Pós-Graduação em Direito PPGDir./UFRgS | Edição Digital | Porto Alegre | Volume X | Número 3 | 2015 | P. 90 - 111 


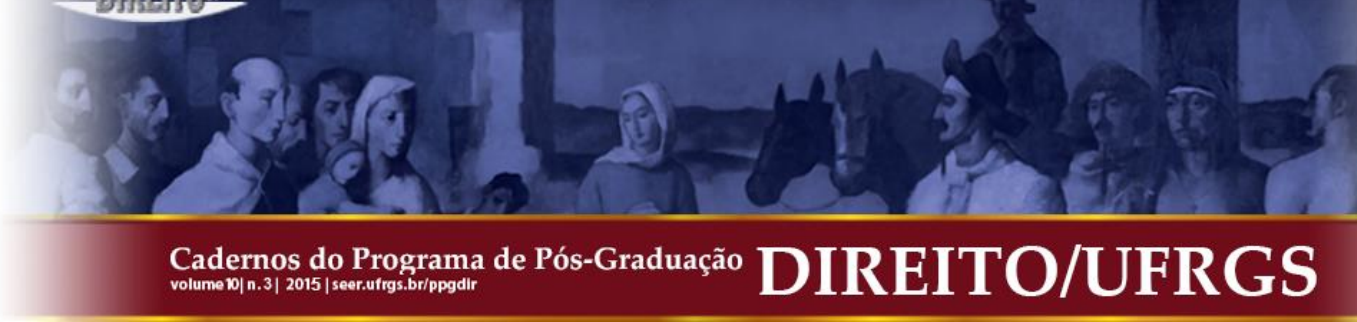

demonstrado que nenhum outro princípio dá maior peso às visões de qualquer membro individual, exceto dando a suas opiniões maior peso do que o atribuído às de algum outro membro individual. $\mathrm{Na}$ verdade, o método de decisão majoritária tenta dar à opinião de cada indivíduo nesse processo o maior peso possível que seja compatível com um peso igual para as opiniões de cada um dos outros.

A decisão majoritária justifica-se porque o consentimento individual tem igual importância na deliberação coletiva. Nesse contexto, para Waldron, o indivíduo deve ser considerado como alguém com capacidade moral, isto é, alguém com capacidade de pensar a relação moral entre seus interesses e os interesses dos outros, o que constitui uma competência democrática básica. ${ }^{63}$ É a contraposição de Waldron a um modelo egoísta de deliberação em que os indivíduos decidem considerando aspectos utilitaristas. Entretanto, Waldron ressalva que a deliberação entre sujeitos morais responsáveis não implica a eliminação da discordância. Pelo contrário, nesse modelo de discordância, homens e mulheres debatem passionalmente e ferozmente sobre os direitos que supõe possuir e sobre as questões a respeito do que é justo. ${ }^{64} \mathrm{E}$ Waldron conclui que não se deve ter vergonha dessa discordância, uma vez que a discordância é o melhor sinal nos dias de hoje de que o povo leva os direitos à sério. ${ }^{65}$

Entende, assim, que se (1) as instituições democráticas estiverem funcionando bem, com um legislativo eleito de acordo com os princípios representativos, (2) se o Judiciário atua com independência, (3) se há um comprometimento da maioria dos membros da sociedade e de seus agentes público com a ideia de indivíduo e de direitos da minoria e (4) há uma persistente, substancial e de boa-fé discordância sobre os direitos, a decisão coletiva cabe ao legislador, devendo ser afastado o judicial review. É o que Waldron chamou de o núcleo do caso contra o judicial review. ${ }^{66}$

Portanto, para Waldron, o Parlamento ocupa um lugar central, repudiando o que denominou de supremacia judicial. Entretanto, mesmo com essa forte ênfase, o autor não descarta o judicial review. Dessa maneira, em alguns casos, Waldron admite o judicial review, como, por exemplo, para o caso das minorias discretas e insulares. Contudo, ressalva o autor que essa concessão ao judicial review não invalida o seu argumento, na medida em que a intervenção judicial se justifica para se reparar as falhas do sistema representativo, o que

\footnotetext{
${ }^{63} \mathrm{Id}$, Law and Disagreement. New York, Oxford University Press, 2004. p. 282.

${ }^{64}$ Ibid, p. 305.

${ }^{65}$ Ibid, p. 311.

${ }^{66}$ Ibid, The core of the case against judicial review. Yale Law Journal, v. 115, 1346, 2005-2006.
}

Cadernos do Programa de Pós-Graduação em Direito PPGDir./UFRGS | Edição Digital | Porto Alegre | Volume X | Número 3 | 2015 | P. 90 - 111 


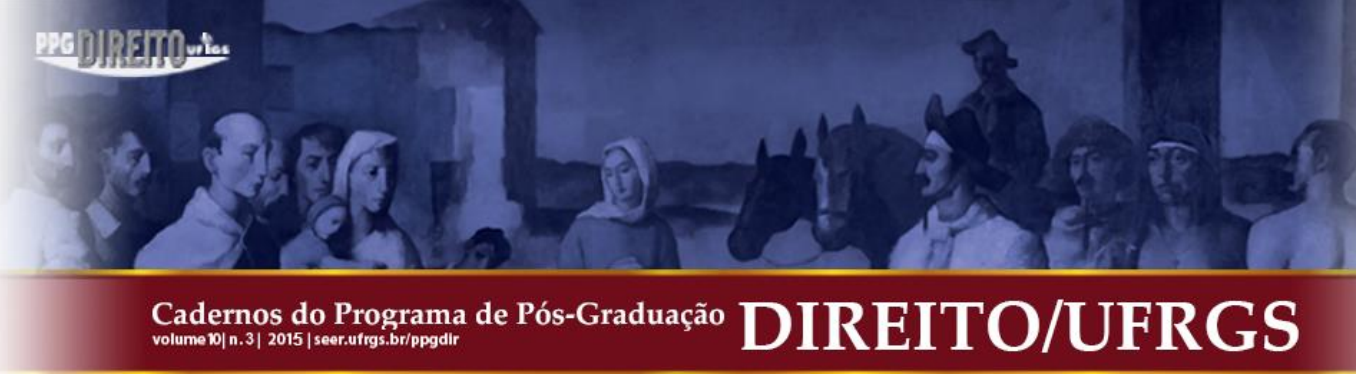

concepção de obrigação política está mais impregnada da noção protestante de fidelidade a um sistema de princípios. E é esse último aspecto que aproxima Dworkin de Waldron.

Waldron rejeita também o modelo de democracia liberal da competição que denomina de fisicalista. A concepção de democracia de Waldron tem como suposto a inevitável discordância sobre questões de justiça e a necessidade de ação política. Para Waldron, como a discordância é um problema insolúvel e as deliberações políticas não podem ser delegadas pela comunidade política. Propõe então um paradigma de democracia, cuja premissa fundamental é a do consentimento individual. A unanimidade é necessária para a formação da sociedade política por meio do contrato social. Entretanto, a celebração do contrato social e, por seu turno, a formação do Estado, não implica a abolição da liberdade individual que ainda permanece, sendo os indivíduos convocados a participar das deliberações da vida política. Segundo Waldron, o consentimento individual funciona como trunfo do indivíduo. Para que haja deliberação política, é necessário o consentimento individual, e somente são aprovadas as proposições que nasceram de iniciativas de indivíduos. O critério majoritário é empregado porque confere igual peso as visões de mundo de todos os indivíduos da sociedade. E as deliberações políticas são realizadas por indivíduos dotados de uma competência democrática básica, a de considerar seriamente os seus interesses e os dos demais membros da comunidade política. Por esse motivo, embora haja feroz discordância, os indivíduos, enquanto comunidade política, são aqueles capazes de levar os direitos a sério.

E é nesse ponto que mais uma vez convergem. Os modelos teóricos de democracia dos dois autores supõem indivíduos virtuosos. Em Dworkin, a obrigação política equivale a um ato de fidelidade protestante. Em Waldron, os indivíduos são dotados de maneira inata de um senso de justiça que os torna aptos a deliberarem seriamente sobre os direitos da comunidade política.

Em contraponto ao modelo de democracia liberal de competição e disputa, tanto Dworkin como Waldron propugnam, ao meu juízo, um modelo extremamente idealizado, na medida em que a capacidade de levar os direitos a séria é depositada na ideia de fidelidade protestante e de senso de justiça inato, ou seja, em um padrão de conduta ascético e na aptidão genética de se ter igual consideração pelo direito de todos.

O que difere é a arena em que a disputa é travada. Evidentemente, não são autores ingênuos. $\mathrm{O}$ desrespeito aos direitos fundamentais e a discordância feroz sobre visões de justiça são realidades que não escapam do horizonte de problematização dos dois autores.

Cadernos do Programa de Pós-Graduação em Direito PPGDir./UFRgS | Edição Digital | Porto Alegre | Volume X | Número 3 | 2015 | P. 90 -111 


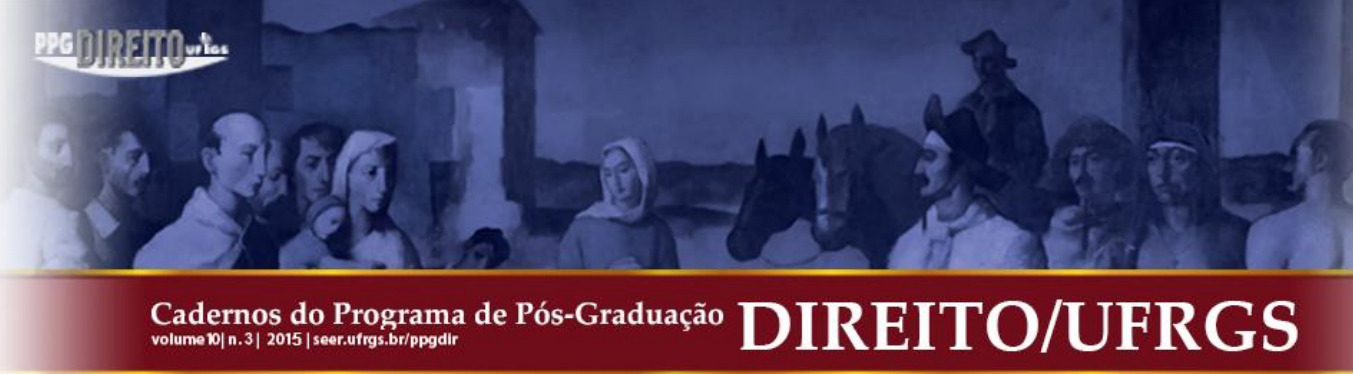

Entretanto, para Dworkin, os direitos fundamentais são trunfos do indivíduo, uma vez que, é no âmbito do Poder Judiciário, que o indivíduo pode travar a disputa pelos seus direitos a fim de que sejam levados a sério. Em Waldron, o trunfo é o consentimento do indivíduo. A aptidão e a opção de participação do indivíduo nas deliberações políticas é o que torna legítima a democracia, isto é, a vinculação de decisões coletivas em meio a uma feroz discordância. A arena de disputa é o parlamento.

E, nesse ponto, tem-se outra distinção. Em Dworkin, não há diálogo institucional. A primeira e última palavra é a do Judiciário. Na hipótese de o Judiciário errar, resta o recurso a desobediência civil. A obrigação política é de fidelidade aos princípios jurídicos da comunidade política. Assim, a comunidade política é fiel aos direitos fundamentais e não ao Poder Judiciário.

Em Waldron, a última palavra é do Parlamento, é da comunidade política. A obrigação política fundamental é de respeito as decisões coletivas oriundas da deliberação política da comunidade política. Contudo, Waldron faz uma concessão ao Poder Judiciário. Reconhece que a intervenção judicial é necessária para a proteção das "minorias discretas e insulares", que se encontram desprotegidas no âmbito de sistema de deliberação política em face das fragilidades operacionais de uma democracia representativa.

E a última convergência entre os dois autores. O respeito aos direitos fundamentais é uma obrigação política da comunidade política. Em Dworkin, a ideia de fidelidade aos princípios jurídicos da comunidade política justifica a desobediência civil. Em Waldron, é a própria deliberação política feroz da comunidade política que implica a possibilidade de se levar a sério os direitos.

\section{CONCLUSÕES}

O caminho trilhado pelas teorias democráticas de Dworkin e Waldron evidencia a estreita relação entre democracia e o conceito de última palavra, isto é, pela ótica institucional a quem compete dar a última palavra sobre o sentido da Constituição. A ênfase de Dworkin é no Judiciário; enquanto para Waldron, o parlamento é o locus privilegiado da última palavra. 


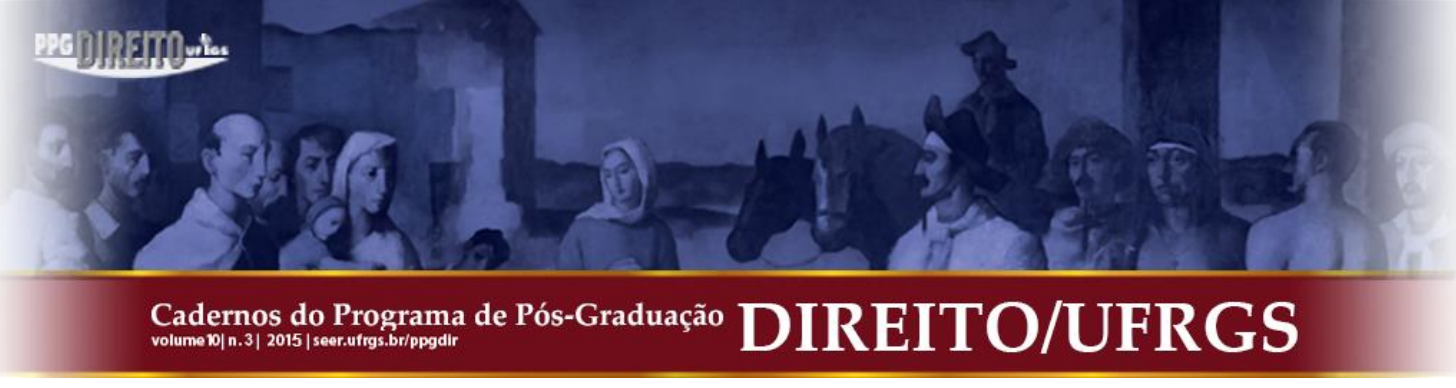

De qualquer sorte, embora haja essa distinção, é importante reconhecer que tanto Dworkin como Waldron repudiam uma visão de uma democracia liberal meramente de freios e contrapesos e advogam um modelo de democracia constitucional de critérios substantivos. E ainda convergem para a importante compreensão de que a obrigação política de respeito aos direitos fundamentais é de titularidade da comunidade política.

O que aponta para um aspecto relevante para a teorização do conceito de diálogo institucional, na medida em que não se pode excluir do conceito de democracia a noção de que a obrigação política de respeito aos direitos fundamentais é de titularidade da comunidade política e, por seu turno, é mais do que natural, é necessário do ponto de vista normativo, que o sentido da constituição e dos direitos fundamentais seja um empreitada dialógica entre os poderes constituídos e, de maneira ampliativa, com a comunidade política como um todo.

Entretanto, como foi visto, tanto Dworkin como Waldron, comungam de uma perspectiva idealizada do indivíduo, o que sobrecarrega normativamente o conceito de democracia de ambos, isto é, se impõe um ônus dialógico racional ao indivíduo que inviabiliza a própria democracia.

E essa é a objeção apresentada pelos defensores de uma democracia liberal competitiva. Foi o que Madison defendeu, tendo do lado oposto os antifederalistas, como acentuou Gargarella ${ }^{70}$ :

Assim, a afirmação madisoniana segundo a qual os homens não eram anjos tem um destinatário preciso: a visão, que parece presente em muitos republicanos (antifederalistas) que se opunham à Constituição, quem sustentava que as personas atuavam ou podiam atuar, coletivamente, motivadas pelo puro ou fundamental desejo de servir aos demais e, por consequência, aos interesses de sua comunidade.

O diálogo institucional é uma realidade empírica inquestionável. Entretanto, a justificativa normativa por uma teoria dialógica de construção do sentido da Constituição depende do modelo teórico de democracia. Oscila-se entre um modelo de indivíduos virtuosos a um de indivíduos egoístas. Será que as alternativas são a dos anjos ou dos demônios? Ou

\footnotetext{
70 “Así, la afirmación madisoniana según la cual los hombres no eran ángeles tenía un destinatário preciso: la visión, al parecer extendida entre muchos republicanos (antifederalistas) que se oponían la Constitución, quienes sostenían que las personas actuaban o podían actuar, colectivamente, motivadas por el puro o fundamental deseo de servir a los demás y, em consecuencia, a los intereses de su comunidade." (Tradução nossa livre do espanhol.) GARGARELLA, Roberto. El nuevo constitucionalismo dialógico frente al sistema de los frenos y contrapesos. In: GARGARELLA, Roberto (comp.). Por una justicia dialógica. El Poder Judicial como promotor de la deliberación democrática. Buenos Aires: Siglo Veintiuno, 2014. p. 2475-2480.

Cadernos do Programa de Pós-Graduação em Direito PPGDir./UFRGS | Edição Digital | Porto Alegre | Volume X | Número 3 | 2015 | P. 90 -111
} 


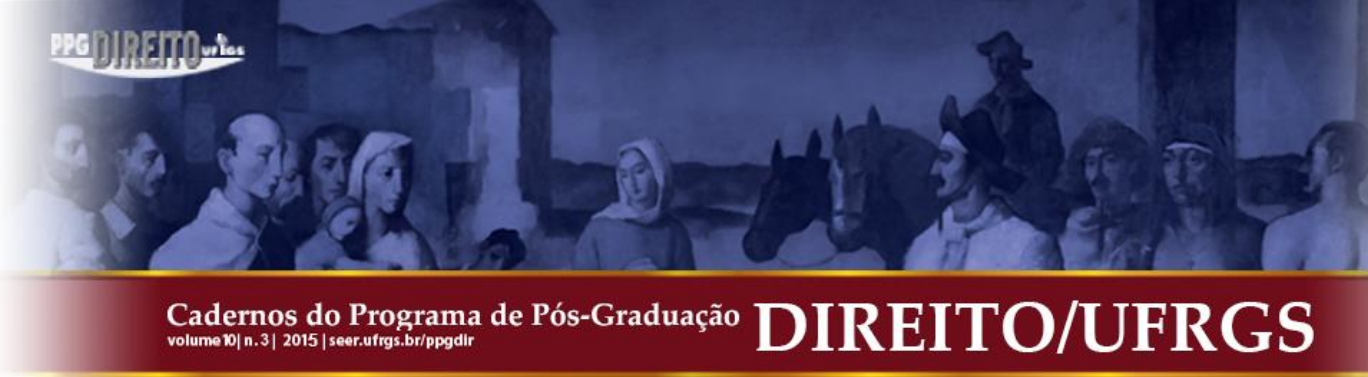

não existe a opção teórica de democracia que considere aquilo que somos: homens e mulheres?

\section{REFERÊNCIAS}

DAHL, Robert. Decision-making in a democracy: the supreme court as national policymaker. Emory L. J., v. 50, p. 56, 2001.

BRANDÃO, Rodrigo. Supremacia Judicial versus diálogos constitucionais: a quem cabe a última palavra sobre o sentido da Constituição? Rio de Janeiro: Lumen Juris, 2012.

CAMPOS, Francisco. Estado Nacional. Disponível em: <http:www.ebookbrasil.org/eLibris/chicocampos.html>.

DWORKIN, Ronald. O Império do Direito. São Paulo: Martins Fontes, 1999.

Uma Questão de Princípio. São Paulo: Martins Fontes, 2000.

. Freedom's Law. The Moral Reading of the American Constitution. Oxford University Press, 2005.

GARGARELlA, Roberto (comp.). Por una justicia dialógica. El Poder Judicial como promotor de la deliberación democrática. Buenos Aires: Siglo Veintiuno, 2014.

HOGG, Peter W. and BUSSELL, Alisson A. The charter dialogue between Courts and Legislatures. (Or perhaps The Charter of Rights isn't such a bad thing after all). Osgoode Law Journal, v. 35, n. 1.

LEVINSON, Daryl J.; PILDES, Richard H. Separation of parties, not powers. Harvard Law Review, v. 119, n. 8, jun. 2006.

MENDES, Conrado Hübner. Direitos fundamentais, separação de poderes e deliberação. Tese apresentada ao Departamento de Ciência Política da Faculdade de Filosofia, Letras e Ciências Humanas da Universidade de São Paulo para a obtenção do título de Doutor em Ciência Política. São Paulo: 2008. 


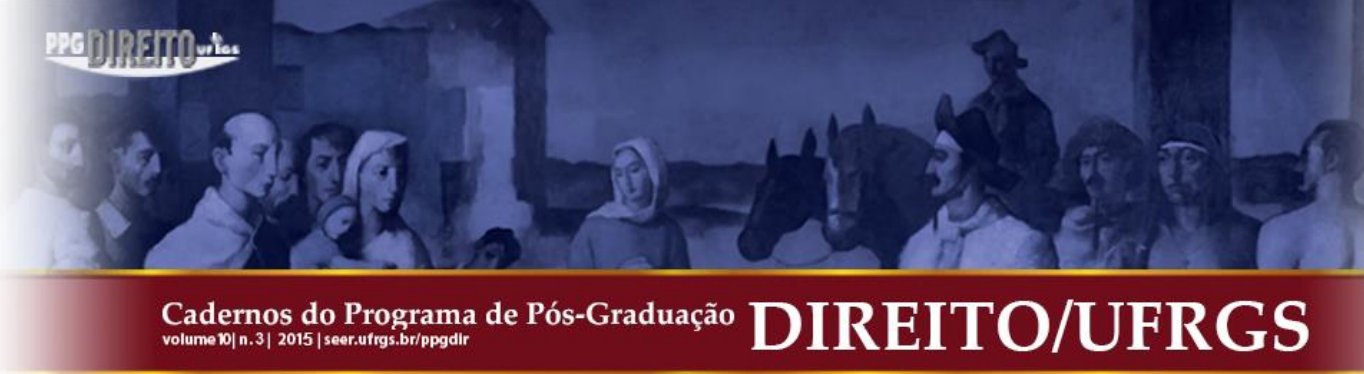

PILDES, Richard H. Is the Supreme Court a "Majoritarian Institution"? New York University School of Law, Public Law \& Legal Theory Research Paper Series. Working Paper n ${ }^{\circ} 11-01$, jan. 2011. Disponível em: 〈http://ssrn.com/abstract=1733169>.

TUSHNET, Mark. Dialogic Judicial Review. Ark. L. Rev., v. 205, 2009.

VICTOR, Sérgio Antônio Ferreira. Diálogo Institucional e Controle de Constitucionalidade: debate entre o STF e o Congresso Nacional. São Paulo: Saraiva, 2015.

WALDRON, Jeremy. A dignidade da legislação. São Paulo: Editora Martins Fontes, 2003.

. Law and Disagreement. New York, Oxford University Press, 2004.

2005-2006

The core of the case against judicial review. Yale Law Journal, v. 115, p. 1346,

Judicial Review and Judicial Supremacy. New York University School of Law, Public Law \& Legal Theory Research Paper Series. Working Paper $n^{\circ}$ 14-57, nov. 2014.

Submissão: 06/09/2015

Aceito para Publicação: 22/12/2015 
